\title{
Research \\ Hybrid Knowledge: Place, Practice, and Knowing in a Volunteer Ecological Restoration Project
}

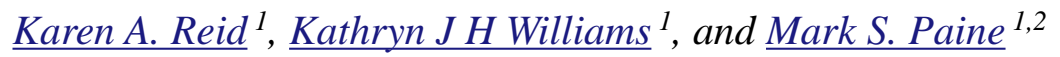

\begin{abstract}
Wide community participation in ecological restoration projects is encouraged because of the multiple values generated. However, it is often assumed that volunteer projects cannot contribute to the production of generalizable ecological knowledge because they are locally focused and don't follow scientific protocols or ecological theory. Anecdotally, the many successful volunteer projects suggest that some amateurs possess insight that could benefit restoration ecology generally, but the processes of generating, testing, and sharing local restoration knowledge remains poorly understood. This ethnographic study of the volunteer restorationist organization, Friends of Organ Pipes National Park, in Victoria, Australia, explores local ecological knowledge generation. Our results suggest that there are similarities between amateurs' knowledge practices and traditional ecological knowledge such as extended apprenticeships, narratives, and the importance of experience of place. There are also similarities with practices of science, for example, semistructured planning, monitoring, evaluating, and documenting observations. We conclude that the ways amateurs generate, share, and test knowledge are complex and dynamic, producing a kind of hybrid between local and scientific knowledge.
\end{abstract}

Key Words: community-based ecological restoration; ecological knowledge; ecological restoration practice; place-based knowledge; traditional ecological knowledge

\section{INTRODUCTION}

One of the strengths of ecological restoration as a landscape management practice is its capacity to engage people from all sectors of the community. Arguably ecological restoration was, from its beginnings, practice-oriented and carried out largely by amateurs on a volunteer basis (Gross 2002). Ecologically and socioeconomically, restoration is a practice that accelerates recovery of damaged or degraded ecosystems and therefore recovery of ecosystem services. Culturally, ecological restoration promises to renew the human relationship with nature, through personal fulfillment and shared experience and meaning making (Clewell and Aronson 2007). Wide community participation in the practice has been encouraged for all these reasons, and to build strong community commitment to restoration projects (Higgs 2003). However, participation by lay members of the public can also be perceived as a weakness. Volunteer-based projects are often considered to be locally specific and therefore lacking potential to contribute significantly to catchment or landscape-scale outcomes, or to the production of valid and generalizable knowledge (Lake 2001, Palmer et al. 2006, Clewell and Aronson 2007). There is speculation about whether practitioners follow ecological principles in regard to application of theory to goal setting and practice (Hobbs and Norton 1996). Further, it is thought that many practitioners fail to follow scientific practices of hypothesis testing by experiments, or protocols of monitoring and reporting. Nevertheless, as Hobbs (2006) observes, many local projects are successful, which suggests that some practitioners possess considerable insight from which restoration ecologists should endeavor to learn. Much is known, or at least assumed, about how scientific knowledge is generated, but to date there have been few empirical studies into the processes by which local ecological restoration knowledge is generated, tested, and shared among participants. In this paper, we describe research conducted to explore these processes of knowledge production. 


\section{Studies of volunteer restoration}

Most studies of volunteer ecological restoration practice focus on the extent to which participants can or do follow scientific protocols. Such studies are premised upon a deficit model of public understanding of science that assumes lay people are unable or unwilling to engage with complex science (Wynne 1991). However, as Bernhardt et al. (2007) found, the absence of monitoring for example, can be because of a lack of funding rather than lack of will, and as such is a source of frustration to practitioners. Our research focus is on volunteer restorationists as innovators in their own right rather than as practitioners who vary in the degrees to which they implement the science.

The knowledge practices of the Volunteer Stewardship Network (VSN) in Illinois, USA has previously received scholarly attention. Steve Packard, founding member of the North Branch Restoration Project, a member organization of the VSN, described the group's practices as being trial and error using hundreds of uncontrolled experiments. This process has the benefit of delivering results earlier and at lower cost than a more systematic approach (Packard 1988). Packard's account of one such experiment is:

I remember very well the day (recorded in my notebooks as April 5, 1980) when a former brush patch began its contribution to science. First we seeded the bare ground of the patch. Then I raked the same density of seed into a strip two feet wide and extending six feet east through the old-field turf. I suspected that no prairie would grow from that dense competition. But I wanted to know for sure. Now we could compare two very differently prepared pieces of ground, planted the same way at the same time. We could also compare both to adjacent areas that we had left alone. That's science. (Packard 1994:34-35)

Some members of the scientific community however, took issue with Packard's claim that the volunteers were practicing a form of science. The academic argument was not necessarily that the volunteers could not achieve restoration objectives, but rather that the way volunteers practiced restoration would not produce generalizable knowledge that could guide future work (Helford 1999). In his study of the differing academic and volunteer discourses of restoration science, Helford (1999) argued that VSN members defined their science through their relationship with the landscape, seeing themselves as working within the ecosystem as part of nature, rather than apart from it. According to Helford (1999:67) the volunteers "made it clear that they envisioned their approach to 'knowing' the ecosystem as one that cultivated a 'feeling for the organism." In the view of the volunteers, the production of new knowledge comes as much from the practical activities associated with restoring ecosystems, which involves craft and intuition, as it does from controlled, systematic experiments. Packard pithily noted that the data he used to judge the outcome of the volunteers' restoration experiments was that "I looked at it with my eyes" (Helford 1999).

The argument here is about the supposed rigor, objectivity, and universal applicability of science and the scientific method contrasted with the assumed lack of rigor, subjectivity, and local applicability of all other modes of knowledge production. Helford's (1999) study demonstrated that the North Branch volunteers' approach to generating and testing restoration knowledge is very closely tied to being in and experiencing the ecosystem. The interaction between science and local knowledge is presented as a contest about the social meanings made of the different modes of knowledge production. Helford seems to imply that the two ways of knowing are as a result, impenetrable to each other. Agrawal (1995) critiqued the assumed dichotomy between western scientific and other modes of knowledge. For example, whereas western science is supposed to be systematic, objective, and open to change in the face of contradictory evidence, local or traditional knowledge is assumed to be closed, nonsystematic, and devoid of rigor and objectivity. Further, Agrawal (1995) argued that there is evidence that what we think of as traditional knowledge has, for centuries, interacted with western knowledge with the result that both ways of knowing are continuously being transformed. Following Agrawal, the grounding assumption for this study was to recognize that contests about knowledge occur constantly, but that these interactions can be dynamic and productive. Our purpose was to better understand how amateur practitioners produce and share knowledge for ecological restoration, and how their process interacts with more formally recognized modes of knowledge production, science in particular. 


\section{METHODS}

\section{Case study site}

A case study of a volunteer ecological restoration was conducted at Organ Pipes National Park, located approximately $20 \mathrm{~km}$ northwest of Melbourne in southeastern Australia. The national park was proclaimed in 1972 to protect features of geological significance (Fig. 1). Geographically, the park is situated in a gorge carved through basalt plains by Jackson's Creek. There are four main landforms and vegetation types. The basalt plain would once have been dominated by Plains Grassland, as well as riparian zones, rocky escarpments, and sedimentary outcrops that supported various types of woodland (Edwards 1974). Ecologically the park was in a highly degraded state. Edwards (1974:21) noted that "twenty-four proclaimed noxious weeds between them covered nine-tenths of the area." The National Parks Service's management aim was to "...restore the highly modified environment of Organ Pipes National Park to a condition as similar as possible to that obtaining at the time of first European settlement ... with certain exceptions propagating material for re-vegetation purposes should be collected from within the present Park" (National Parks Service 1972). A local environmental group, who became the Friends of Organ Pipes National Park, grasped the opportunity for some hands-on conservation in one of the few protected remnant grasslands in their region. The importance of their role in making the aim of restoration a reality has been acknowledged (Edwards 1974). The park is currently managed by the Victorian state government agency Parks Victoria. The Friends of Organ Pipes National Park, commonly known as FOOPs, have had an ongoing, unbroken involvement in its restoration. Membership has been stable and they have entered their third generation of leadership. This case study presented the researchers with an opportunity to observe how knowledge, technologies, and practices developed over time in a long-term community-based project.

\section{Data collection and analysis}

Data collection was carried out via participantobservation and in-depth unstructured interviews. The principal researcher spent 19 months as a participant-observer with FOOPs, attending workdays, known locally as 'working bees,' and committee meetings. During that period, FOOPs' work was focused on two contrasting sites within the park, Main Flat and Costas Block. Main Flat was one of the first sections of the park regenerated and the group is now coming to grips with the outcomes of decisions made before much was known about doing ecological restoration. Costas Block on the other hand became crown land in 1995 and FOOPs began planting in 2000 (Bender 1995, 2000). Although it is impossible to record everything seen and heard, notes were made about observations broadly related to theoretical knowledge and practical know-how, becoming increasingly focused as themes and patterns emerged (Hammersley and Atkinson 2007). May (1997) stresses the importance of including details of the physical locations of interactions in field notes, and Helford's (1999) work also highlights the significance of restorationists' relationship with the landscape to understanding the generation and application of knowledge. Participant-observation and use of field notes gave the researcher access to interactions and conversations taking place between people over an extended period of time. For example, it was possible to observe how the stories shared among group members during work days evolved and incorporated new information over months and years.

Interviews were conducted after the participantobservation fieldwork had commenced and so were grounded in some understanding of FOOPs' practice. Four of the five members of FOOPs informal committee structure were interviewed, along with two other regular contributors who are not committee members. One participant has a formal tertiary education in an environmental science, and one other works in the ecological restoration industry. All but one had been a member of FOOPs for more than 20 years. We also interviewed three park rangers from Organ Pipes. Finally, we interviewed one academic ecologist who had worked alongside FOOPs because of their shared interest in a population of remnant Murray Pine (Callitris glaucophylla) adjacent to the Organ Pipes National Park. The interviews explored restoration themes such as information gathering and learning, problem solving, and use of published science. With the permission of participants, interviews and committee meetings were digitally recorded and transcribed for analysis.

Data analysis was an iterative process. The first phase entailed detailed and repeated reading of the data to capture emerging themes and patterns and 
Fig. 1. The escarpment at Organ Pipes National Park showing the distinctive geological feature that gives the park its name.

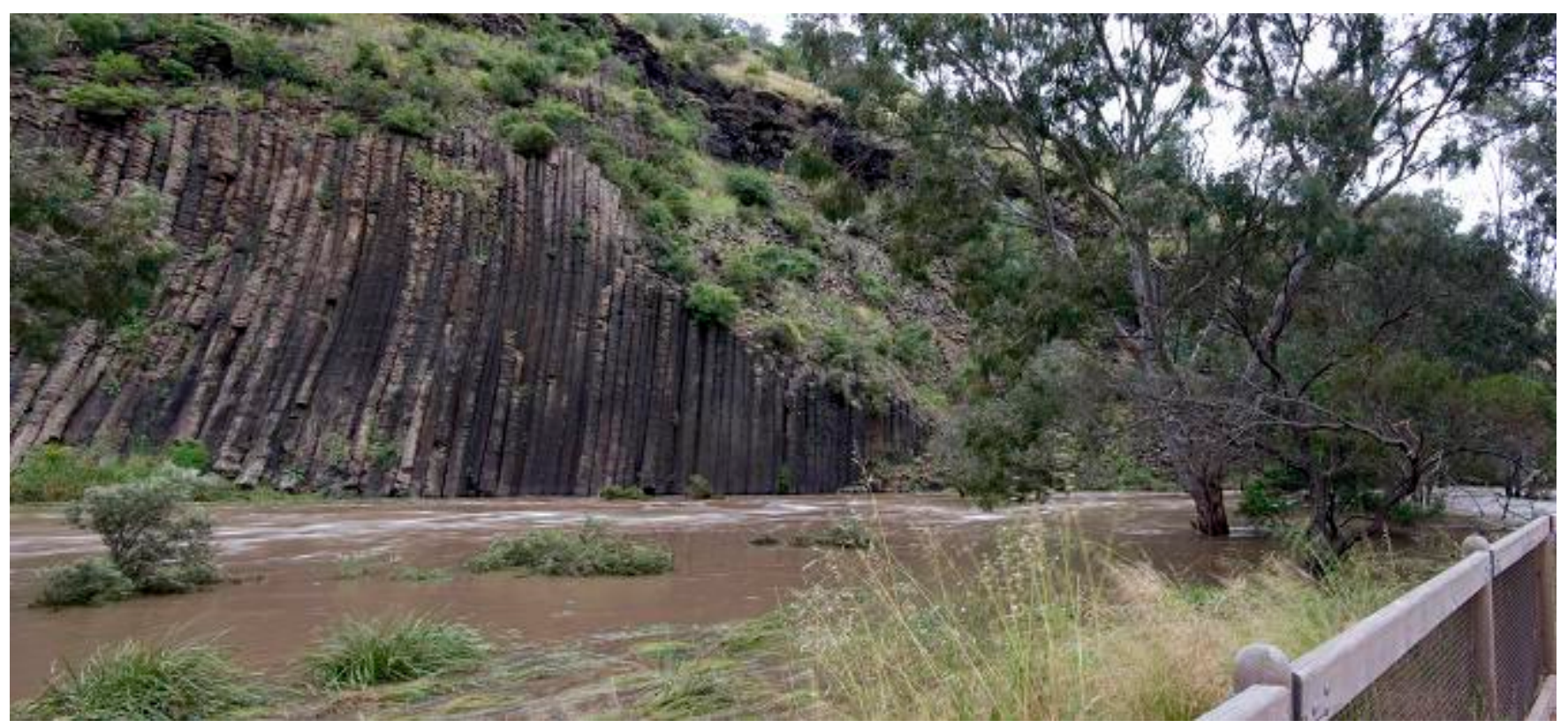

to write analytic memos linking data to theory (Hammersley and Atkinson 2007). The overwhelming theme to emerge was the way that FOOPs use narratives of place and of tradition in their knowledge making and sharing. We explained this by using theories of organizational sensemaking (Weick 1995), which highlights the importance of story-telling and in particular, narratives about predecessors and tradition to collective knowledge generation and sharing. Sensemaking was complemented by place theory, most specifically the concept of inscribed space, which implies that people embed their experience into the landscape by the meanings they attach to places and the memories that places hold (Low and LawrenceZúñiga 2003).

We acknowledge the limits to generalization from a study focused on one group and one ecological restoration project. However, we argue that the value of this research is its contribution to an area of knowledge that has not previously been well explored and that will be of benefit to restoration ecologists.

Pseudonyms are used throughout this paper to conceal the identity of study participants.

\section{RESULTS}

\section{Generating knowledge}

There were limited published knowledge resources accessible to FOOPs when they began restoring the flora at Organ Pipes. The science of restoration ecology was yet to be established and there was a dearth of written information about Plains Grassland flora generally. Group member John recalls his early experiences:

\section{I became very active in grassland flora restoration in the late seventies ... and back in those days if you wanted to learn something about the local flora there weren't any books on the subject so you just had to knock around with anybody else that you could find that knew a little bit and share knowledge and learn that way.}

For FOOPs in the 1970s and 1980s two of the most significant contributors to knowledge sharing were founding members Don Marsh and Barry Kemp. Neither man had any formal training in biological sciences, but irrespective of their amateur status Kemp and Marsh are regarded as having set the 
standard for ecological restoration in the Melbourne area. Long-time FOOPs member John, who also works in the restoration industry, notes:

...a lot of people giving talks on reveg (etation) will frequently refer to the Bradley method. Now the likes of Don Marsh and Barry Kemp could have written a book about reveg works and had they written the book then their book would have more relevance to work in the Melbourne area than the Bradley book and people would be referring to planting as the Kemp and Marsh method because they're pioneers in the field and I've been preaching their methods for years.

The Bradley Method for bush regeneration was developed in the 1960s for application in remnant patches of indigenous vegetation in the suburbs of Sydney. The central idea was that hand removal of weeds would allow indigenous vegetation to reestablish from the soil seed bank. The Bradley Method's first principle was to work from the 'good', i.e., most ecologically intact areas first (McGhee 2007). This was problematic for restoration of Organ Pipes as there was little remnant vegetation and no areas that could be described as 'good.' Therefore a first challenge was to reconstruct what the original vegetation structures would have been and develop practices of harvesting and germinating seed and plant establishment. One of Kemp's major contributions was the development of a system of planting zones as a guide for restoration that formed the basis of this process. Kemp drew extensively on historical accounts from such sources as the journals Victorian Naturalist from the first decades of the 20th century, or Proceedings of the Royal Society of Victoria to begin to compile potential plant species lists. He then included observations made at remnant vegetation sites near the Park; current restoration ecologists would call these "reference sites." Kemp also noted emerging patterns of plant associations could be grouped along geological lines, with distinct differences between exposed basalt plains and the river gorges. Kemp concluded that the Park could be divided into habitat zones based on soil, drainage, and aspect each with its distinct plant communities (Kemp and Irvine 1993). The system was adopted by park management and is still in use (Parks Victoria 1998). The academic ecologist interviewed for our study acknowledged Kemp's work as ahead of its time:

\begin{abstract}
That must have been almost a first for someone to sit down, look at the zones they had, figure out what they thought might work in those zones given what they were starting with and then be game enough to publish it ... I reckon that was really admirable that they had enough confidence to do that. If you look out there now, it's worked pretty well I reckon.
\end{abstract}

Although all interviewees exhibited knowledge of the planting zones including species and boundaries, at no point during the fieldwork were any participants observed to refer to them in their documented form (a map). It begs the question of how knowledge of planting zones developed by Kemp during the 1970s has been transferred to current members.

\section{Old stories, new knowledge: testing restoration theory}

FOOPs members describe basic learning about the park and its restoration through an informal apprenticeship. Rupert describes how he learned about the park and its management:

Those two [Kemp and Marsh] supervised virtually all of the early working bees that I attended and knowing that most people come along in a state of total ignorance like me, they taught people about species, about planting techniques. In chats at lunchtime, lots of talk about the history of the park and why decisions were made to do various things and the principles they were using ... so it wasn't a systematic course or anything, but you just picked bits and pieces up.

The apprenticeship process is ongoing. During field studies, FOOPs' veterans were frequently observed to initiate new members by telling them the stories of the places visited, i.e., the theories behind planting decisions, what has been learned, and what should be done in future.

The talk at a workday serves a greater purpose than simply passing on to newcomers the knowledge generated by predecessors. In their talk, FOOPs made comparisons between contemporary observations and stories of what was done in the past. Furthermore, these comparisons were sometimes used to assess current observations against broader 
theories of ecological restoration and FOOPs' restoration objectives. In this way, stories play a role in generating new and more complex understandings. The following field note extract demonstrates how on a walk through the park, FOOPs try to make sense of what they see happening around them by comparing their observations with their goals as restorationists and overarching ecological restoration principles. Each participant in this conversation has been integrally involved in the restoration of Organ Pipes for more than 20 years. All identify as amateurs, without specific environmental/ecological qualifications or occupations.

On the walk to Costas Block, as we passed the old (original?) casuarina plantings, discussion began mostly between Martin and Rupert, but Vincent was there too, about priorities for the next few planting seasons. Rupert is adamant that casuarinas must be planted as the originals were dying and there has been no natural regeneration. Martin was quite set against the idea, not the planting of casuarinas per se, but it was more about applying certain principles to setting priorities. His line was that if the objective in the park is to get natural regeneration, consistently going back and replanting where that has not occurred is defeating the purpose. Where that natural regeneration is not happening, Martin doesn't want to see the group spending the next 10 years planting casuarinas at the expense of higher priorities. Rupert disagreed, essentially saying that casuarinas have to be a high priority if the group is to avoid the sort of disaster that befell the wattle population on the Main Flat. (Extract from field note)

The disaster to which Rupert refers was the en masse deaths of Late Black Wattle (Acacia mearnsii) and Silver Wattle (A. dealbata) in the 1990s, about 20-25 years after planting. There had been no natural regeneration because of predation by rabbits, and no follow-up plantings. However, during the past two to three years there has been natural recruitment and the narrative has evolved into one of managing a regenerating population and explaining the changes (Fig. 2). The stories of events that happened decades ago remain an important part of sensemaking today. Furthermore, this conversation suggests that FOOPs clearly understand the objectives, theory, and principles of ecological restoration. The dilemma they face is one that has been canvassed in contemporary literature of restoration ecology. Although a restored ecosystem is understood as one that is "self-sustaining to the same degree as its reference ecosystem, and has the potential to persist indefinitely under existing environmental conditions" (SERI Science \& Policy Working Group 2004:4), there are acknowledged uncertainties as well. Clewell and Aronson (2007) for example noted two potential impediments to putting the principle into practice, i.e., the degree and severity of human induced degradation, and the loss of traditional management practices, e.g., burning. The conversations that take place in the field of FOOPs practice could be a valuable input into the broader discourse of ecological restoration and to resolution of the dilemmas about putting theory into practice. However, no mechanisms exist to facilitate the wider conversation, perhaps because there is no recognition within the scientific community of amateur practice to contribute to the extension of theory.

\section{Practice meets science}

Ecological restoration is defined as "the practice of restoring ecosystems as performed by practitioners at specific project sites, whereas restoration ecology is the science upon which the practice is based" (SERI Science \& Policy Working Group 2004:11). Accordingly it is often assumed that the appropriate relationship between science and practice is a one way transfer of knowledge from scientist to practitioner. Evidence gathered in this case study suggests that the relationship is far more complex. FOOPs describe the benefits of working side by side with scientists who carry out their research at Organ Pipes and in particular, the knowledge exchange that occurs if a scientist attends workdays. Rupert comments on the role played by a botanist researching Plains Grassland flora in the park: "He came along to working bees and gave us lots of advice ... he was very keen to involve people in his research and he ... eventually came up with some things we actually could help with."

FOOPs however, also understand that scientists objectives may differ from their own and they assess scientific information on that basis. For example, FOOPs member Martin explains the different approaches to knowledge about the park's population of sugar gliders (Petaurus breviceps): 
Fig. 2. The Main Flat at Organ Pipes National Park showing the overstorey of established Eucalypt plantings and understorey of naturally regenerating Acacias.

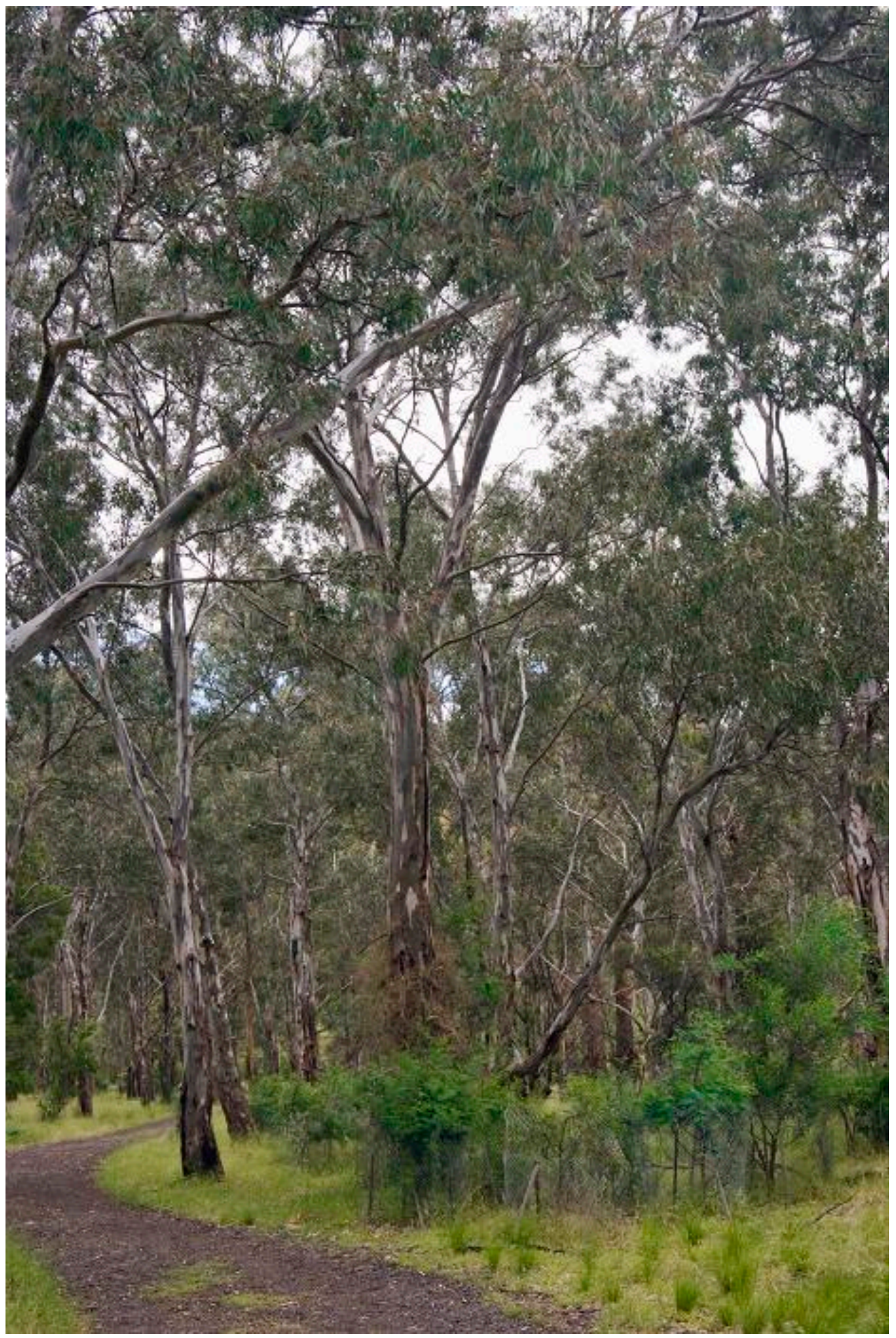




\begin{abstract}
When we first had our research with the sugar gliders, all our interest was to see if the project overall had been a success. You put boxes up, you reintroduce your sugar gliders into the area. Will the population be sustaining? Is it a success for wildlife management, whereas the researcher who came in, she wanted to do some incredible detailed thing about working out whether the male offspring in a family, how they related to the other males in the family or something very very precise, very very narrow... there was no advantage in that for wildlife management and about moving animals into different areas. So that didn't really interest us.
\end{abstract}

FOOPs' management agenda and the questions that arise from it drive their process of sorting out what types of scientific information they will pick up and use. When questions and problems arise, FOOPs members actively seek scientific information from a range of sources. For example, at interview, Tony gave a detailed account of how he researched the apparent lack of natural regeneration of the park's Casuarinas. He described the ease with which scientific information can be accessed from scientists' internet web sites. Having obtained relevant information, Tony then collected seeds from trees in eight different parts of the park and examined them for evidence of a fungus predicted to affect germination, finding that the majority were affected. He then conducted germination and growing trials. Ultimately the trials didn't give him the definitive answer he was looking for, an experience with which most scientists would be familiar. But what is significant is his process. He needed to make sense of the information he found on the internet by conducting his own ad hoc experiments. He has no scientific training and yet he was working with some fairly technical information about the seed morphology and integrating it with his knowledge of the ecology and geography of the park.

Another example of the dynamic interaction of science and practice is in participants' accounts of how FOOPs responded to the 1994 Review of Revegetation at Organ Pipes National Park, Sydenham Victoria commissioned by the Victorian Department of Conservation and Natural Resources. The review's stated benchmark for restoration success at the park was that the "absolute measure of successful revegetation or vegetation restoration is that planted or revegetated populations persist and increase..." (Carr and Muir 1994:25, emphasis in original). The authors concluded that "In view of the experience so far at OPNP, recruitment of indigenous species is likely to remain an uncommon or rare event for most species" (Carr and Muir 1994:27).

FOOPs member Liam recalls that the group "didn't believe" that there was no regeneration occurring and so they set about trying to find some proof. Liam continues:

Rupert and a few others went out to have a look to see what was happening. They knew there was all this seed coming out of the Callitris, but we thought there was no regeneration happening but thought there should be. I think Vincent and Rupert were the ones who first started crawling around on their hands and knees, and actually saw that there was all these little seedlings coming up. But of course there were still a lot of rabbits in those days, and so it would get to a certain stage and then be eaten away. So they started to get a ... rabbit proof fence, so they actually went around and they noticed these little seedlings coming up, and they got little plant tags and put them on each one. And it started off with about 20, and the next month they went back and they found another 20 more, and then they kept on doing this until there was about 160 of the little things. And so they then started a monitoring program where they went along and they measured it each month. Then due to the drought and whatever else, some of them started dying off, but they kept it going for probably five or six years of actually measuring these Callitris ... So that then became an ongoing project... we identified some of the other sites that had Callitris on them that we could apply for grants to make rabbit proof fence around and do the same type of thing. So that has happened in two other areas of the park, where we applied for grants to enclose areas with Callitris in them, and that has been very successful in that we have recruited young plants from those areas. So I guess the impetus was that report saying that there just was not regeneration happening.

In this situation, FOOPs did not passively accept the scientific assessment of regeneration in the park, nor did they merely reject information that 
confronted their view of the park and their role in it. Rather, they were spurred into action to test both their own understandings and those of the scientist. In doing so, they solved the problem. They could now explain the lack of regeneration observed by the scientist and at the same time broaden the scope of their own practice by learning how to take advantage of the natural processes occurring in the park. Furthermore, Liam's description of how FOOPs monitor species populations is worthy of further examination. In the next section we describe how FOOPs monitor, evaluate, and document the outcomes of their work.

\section{Walks in the park: monitoring, evaluating, documenting}

The typical FOOPs workday involves more than the performance of a specified task, e.g., planting or weeding. Some important activities, particularly in the sense of knowledge generation, occur on route to the worksite. On their walks through the park, it is common practice to make detours to places where they've worked in the past. These are opportunities to share stories about places, and with their new observations, continue to build the narrative of restoration in the park. However, the walk is also an opportunity to conduct a more structured form of monitoring and evaluation of past work and their practices. Furthermore, FOOPs publish written accounts of what has been observed. An example of their practice in relation to monitoring the Callitris population, and the way it is recorded in their newsletter follows:

We drove to the freeway gate, jumped the fence and walked across country to the old Callitris site in Sydenham Park to inspect the enclosures with the big trees, stopping at a fenced plot on the plateau in de Benedetto's to admire the grasses and Buttons flowering inside. The upper Cypress pine enclosure looked pretty good, most of the really nasty weeds we used to have to clean out each year now defeated. Afew Artichokes around the rim, but mainly wild Mustard, straggly plants with little yellow flowers. So we spent the morning ripping them out and tossing them over the fence. Inside the original fence line, the Hopbush and Wattles are looking very healthy and all the Callitris seedlings look terrific after the spring rains, bright green and lush. The little patch of Indian Weed is being overrun by Clematis, but still looks healthy... Meanwhile [Liam] walked down to the lower enclosure with poison bottle and saw, removing bits of regenerating Boxthorn. At the bottom end of the enclosure, Spear Grasses and Bluebells are surviving in the shallow loose soil. [Liam] returned to announce that the solitary tree in the enclosure by the creek seems to be dying, about $10 \%$ of its foliage still green, the remainder brown and dead-looking. I took $B$ down the slope for a look. The recent rains may help it recover a little, but it does look far-gone. B had brought a tapemeasure so I was able to measure and map the saplings, which all seem to have grown a lot since last measured in 2001. (Bender 2005)

FOOPs' Newsletters do not follow the conventions of an academic publication, which may for example include comparative data. On the other hand, they vividly describe what is done on workdays, how it was done, and furthermore, alert the reader to the availability of data should they seek it. It contains contextual detail that is sometimes omitted from academic publications, yet is often meaningful to the reader. It is a deliberate strategy by the newsletter editor to make the journal richer than simply listing numbers of species planted or areas of weeds cleared. It becomes part of the ongoing narrative of the park, but also provides a point of reference that can be returned to for comparison in future seasons.

It is the amount of time FOOPs spend 'in place' that puts them in a unique position as 'knowers' in the park. The value of this position is recognized by others including professional park rangers, as one ranger explained:

.... a lot of them [FOOPs] have been around longer than all the staff here, they know the history of the place, they know what has and hasn't worked. They know what the original visions were and I give that a lot of credit and I will listen to what they have to say. I like to provide a good service to the stakeholders and I think that that's what the Friends of Organ Pipes are, one of our really key important stakeholders and they have that much knowledge. That's probably how I see my role and in terms of meeting those objectives, I think they will also play a key part in meeting those objectives, because they are the ones that help bring 
the place forward. They pull out prickly pears that we don't do, we don't really like doing [laughing], but it's the kind of things that just fall by the wayside and they do it. They do this amazing research on the bats that we just wouldn't have a chance to do. They were the ones also I think pushing for the [reintroduction of] sugar gliders...just areas that they know that need attention and they move around to the sites that we don't have time to do.

\section{DISCUSSION}

The data presented here suggests there is merit in further examination of lay ecological restorationists' knowledge practices. FOOPs' knowledge in practice strongly resembles forms of traditional ecological knowledge, particularly in their traditions of storytelling and extended apprenticeships. The importance of traditional ecological knowledge (TEK) is increasingly recognized within restoration ecology, although it is commonly associated with indigenous peoples' knowledge. The Society for Ecological Restoration's position on TEK was, for example, developed by its Indigenous Peoples' Restoration Network (SERI 2008). Weick (1995) however, describes tradition as any human knowhow or action that existed in the past and that has been handed down at least twice over three generations, as is the case with knowledge and practices among FOOPs. Know-how is passed down via traditions learned from predecessors and through the evolving stories they tell about places and past events. Other aspects of FOOPs' knowledge practices also strongly resemble some of the commonly understood characteristics of traditional knowledge. Their knowledge is local, rooted in places and people's experiences in them. It is transmitted orally, or by demonstrations. It is being consistently tested and reinforced by experience, trial and error, and experiments (Ellen and Harris 2000). We do not claim that FOOPs are necessarily representative of all amateur ecological restoration groups; indeed we doubt whether any archetypal restorationist exists. However we do make the observation that because of the similarities between this groups' knowledge in practice and traditional knowledge, continued investigation into what lay practitioners know, and how they know it would be beneficial to the science of restoration ecology. Further, the workday emerges as an important site of knowledge building, where talk, action, and record keeping occur. FOOPs describe the contribution to knowledge building played by scientists who participate in the in-place talk and action sessions, which suggests that workdays may be an ideal occasion for the interplay between restoration ecology and restoration practice.

The results of this study demonstrate that FOOPs do seek and make use of scientific information, but in practice they transform it into something uniquely their own. The process is sometimes evaluative, as observed in Martin's assessment of sugar glider research in terms of FOOPs' wildlife management priorities. There is also an element of locally grounding the general, scientific knowledge, as observed in participants' accounts of the actions they took in response to scientific information about regeneration of flora in the park. Information is made meaningful by how FOOPs put it into practice. Furthermore, parallels with science can be observed in FOOPs' practice. They draw on published science relevant to their management problems, and build on it by trial, monitoring, and ongoing record keeping. This finding mirrors Helford's (1999) observation that VSN volunteers in Illinois saw themselves as both applying and generating knowledge. It is also important to note that scientific uncertainty does not necessarily hinder practice. FOOPs' approach to the uncertainties about Casuarina and Callitris regeneration suggest that, to the contrary, uncertainty may lead to investigation and innovation.

Finally, the results demonstrate the importance of understanding how experience of landscape contributes to the richness of local ecological knowledge. There is an emerging discourse in the literature of restoration ecology that embraces the complexities of landscape. The concept of landscape in restoration ecology is usually understood to mean mosaics of interacting ecosystems (SERI Science \& Policy Working Group 2004). There are however, other ways of understanding landscapes. Moreira et al. (2006:218) explore the concept of cultural landscapes as those that "are produced by the long-term interaction of humans and nature," which recognizes the role humans play in producing landscapes. They describe the restored landscape as an "emerging landscape" that "maintains memories from all the time periods" of its history of degradation and recovery (Moreira et al. 2006:221). Restoration of a cultural landscape takes into consideration both the biodiversity values of ecological restoration as 
well as cultural perspectives. It therefore requires a transdisciplinary approach to understanding that integrates natural science with social sciences, humanities, and local knowledge (Moreira et al. 2006). In this study we have explored how FOOPs generate ecological knowledge through nearly 40 years of interactions with the landscape at Organ Pipes National Park. We argue that this type of longterm environmental stewardship produces an emerging cultural landscape with similarities to those described by Moreira et al. (2006). To fully understand and learn from such projects, research needs to encompass more than the natural ecological processes taking place and begin to embrace questions about how the form and function of the landscape emerges from the human interactions with it.

\section{CONCLUSION}

The ways in which local ecological restoration knowledge is generated, shared, and tested, and the relationship with scientific knowledge is more complex and dynamic than may have been assumed. In some ways, FOOPs practice is similar to traditional ecological knowledge, i.e., the role of narrative to perpetuate and generate knowledge, and the importance of the experience of place. Some of their practices also strongly resemble scientific methods, i.e., experiments and trials, monitoring and evaluating outcomes, and record keeping. FOOPs' pursuit of scientific information is driven by their own management needs. Information that they perceive as potentially improving their practice is likely to be embraced, but only after it has been tested and made locally meaningful. A kind of hybrid knowledge is generated.

These results encourage us to suggest that further research into the practice of amateur ecological restorationists would be of benefit to restoration ecologists. Specifically, we recommend further investigation of the importance of place-based knowledge production and exchange, and understanding of restored landscapes as cultural landscapes that take shape through practice.

Responses to this article can be read online at: http://www.ecologyandsociety.org/voll6/iss3/art19/ responses/

\section{Acknowledgments:}

The authors acknowledge with thanks the support of the Parks Victoria Rangers stationed at the Grasslands Unit at Organ Pipes National Park. We are also grateful for the insightful comments on an earlier draft of this manuscript from our colleague Dave Kendal. We also thank the anonymous reviewers whose constructive suggestions greatly improved our manuscript. We reserve our greatest thanks for the Friends of Organ Pipes past and present whose commitment to learning and sharing their knowledge made this research possible. This study was conducted with the support of an Australian Postgraduate Award.

\section{LITERATURE CITED}

Agrawal, A. 1995. Dismantling the divide between indigenous and scientific knowledge. Development and Change 26:413-39. http://dx.doi.org/10.1111/j .1467-7660.1995.tb00560.x

Bender, R. 1995. Working Bee. FOOPS Newsletter 61, 23 September.

Bender, R. 2000. Working Bee. FOOPS Newsletter 93, 23 September.

Bernhardt, E. S., E. B. Sudduth, M. A. Palmer, J. D. Allan, J. L. Meyer, G. Alexander, J. Follastad-Shah, B. Hassett, R. Jenkinson, R. Lave, J. Rumps, and L. Pagano. 2007. Restoring rivers one reach at a time: results from a survey of U.S. river restoration practitioners. Restoration Ecology 15(3):482-493. http://dx.doi.org/10.1111/j.1526-100X.2007.00244. $\underline{x}$

Carr, G., and A. Muir. 1994. A review of revegetation at Organ Pipes National Park Sydenham, Victoria report. Department of Conservation and Natural Resources, Melbourne, Australia

Clewell, A. F., and J. Aronson. 2007. Ecological restoration: principles, values, and structure of an emerging profession. Island Press, Washington, D. C., USA. 
Edwards, G. 1974. Organ Pipes National Park - a study in applied conservation. Victoria's Resources 16(1):21-24.

Ellen, R., and H. Harris. 2000. Introduction. Pages 1-34 in R. Ellen, P. Parkes, and A. Bicker, editors. Indigenous environmental knowledge and its transformations: critical anthropological perspectives. Harwood Academic, Amsterdam, The Netherlands.

Gross, M. 2002. New natures and old science: hands-on practice and academic research in ecological restoration. Science Studies 15(2):17-35.

Hammersley, M., and P. Atkinson. 2007. Ethnography: principles in practice. Routledge, London, UK.

Helford, R. M. 1999. Rediscovering the presettlement landscape: making the oak savanna ecosystem "real". Science, Technology \& Human Values 24(1):55-79. http://dx.doi.org/10.1177/0162 24399902400104

Higgs, E. S. 2003. Nature by design: people, natural process, and ecological restoration. MIT Press, Cambridge, Massachusetts, USA.

Hobbs, R. J., 2006. Forward. Pages ix-x in D. A Falk, M. A. Palmer, and J. B Zedler, editors. Foundations of restoration ecology. Island Press, Washington, D.C., USA.

Hobbs, R. J., and D. A. Norton. 1996. Towards a conceptual framework for restoration ecology. Restoration Ecology 4(2):93-110. http://dx.doi.org/ 10.1111/j.1526-100X.1996.tb00112.X

Kemp, B., and R. Irvine. 1993. Design and use of planting zones at the Organ Pipes National Park notes on research and planning for the first 20 years. The Victorian Naturalist 110(3):113-124.

Lake, P. 2001. On the maturing of restoration: linking ecological research and restoration. Ecological Management \& Restoration 2 (2):110-115. http://dx.doi.org/10.1046/j.1442-8903 .2001.00074.x

Low, S. M., D. Lawrence-Zúñiga. 2003. Locating culture. Pages 1-47 in S. M. Low and D. LawrenceZúñiga, editors. The anthropology of space and place. Blackwell, Malden, Massachusetts, USA.
May, T. 1997. Social research: issues, methods and process. Open University Press, Buckingham, Pennsylvania, USA.

McGhee, K. 2007. The (bush) revival gospel. Australian Geographic 87:124-131.

Moreira, F., A. I. Queiroz, and J. Aronson. 2006. Restoration principles applied to cultural landscapes. Journal for Nature Conservation 14:217-224. http://dx.doi.org/10.1016/j.jnc.2006.05.007

National Parks Service. 1972. Re-vegetation of Organ Pipes National Park - interim policy. National Parks Service, Sydney, Australia.

Packard, S. 1988. Just a few oddball species: restoration and the rediscovery of the tallgrass savanna. Restoration and Management Notes 6 (1):13-20.

Packard, S. 1994. Successional restoration: thinking like a prairie. Restoration and Management Notes 12:32-39.

Palmer, M. A., D. A Falk, and J. B. Zedler. 2006. Ecological theory and restoration ecology. Pages 1-10 in D. A. Falk, M. A. Palmer, and J. B. Zedler, editors. Foundations of restoration ecology. Island Press, Washington, D.C., USA.

Parks Victoria. 1998. Organ Pipes National Park management plan. Government of Victoria, Melbourne, Australia.

Society for Ecological Restoration International (SERI). 2008. Traditional ecological knowledge. SERI, Washington, D.C., USA. [online] URL: http ://www.ser.org/iprn/tek.asp. Accessed 11 September 2008.

Society for Ecological Restoration International (SERI) Science \& Policy Working Group. 2004. The SER International primer on ecological restoration. SERI, Washington, D.C., USA. [online] URL: http://www.ser.org

Weick, K. 1995. Sensemaking in organizations. Cambridge University Press, Cambridge, UK.

Wynne, B. 1991. Knowledges in context. Science, Technology \& Human Values 16:111-121. http://dx. doi.org/10.1177/016224399101600108 